\title{
Characterization of Particulates from Australian Underground Coal Mines
}

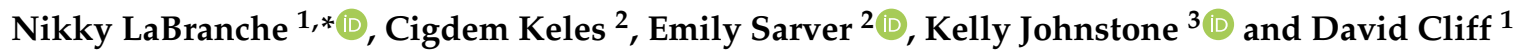 \\ 1 Minerals Industry Safety and Health Centre, Sustainable Minerals Institute, The University of Queensland, \\ Brisbane 4072, Australia; d.cliff@uq.edu.au \\ 2 Mining \& Minerals Engineering, Virginia Polytechnic Institute and State University, \\ Blacksburg, VA 24061, USA; cigdem@vt.edu (C.K.); esarver@vt.edu (E.S.) \\ 3 School of Earth and Environmental Sciences, The University of Queensland, Brisbane 4072, Australia; \\ k.johnstone2@uq.edu.au \\ * Correspondence: n.labranche@uq.edu.au; Tel.: +61-40761-0108
}

Citation: LaBranche, N.; Keles, C.; Sarver, E.; Johnstone, K.; Cliff, D. Characterization of Particulates from Australian Underground Coal Mines. Minerals 2021, 11, 447. https:// doi.org/10.3390/min11050447

Academic Editor: Shifeng Dai

Received: 22 March 2021

Accepted: 20 April 2021

Published: 23 April 2021

Publisher's Note: MDPI stays neutral with regard to jurisdictional claims in published maps and institutional affiliations.

Copyright: () 2021 by the authors. Licensee MDPI, Basel, Switzerland. This article is an open access article distributed under the terms and conditions of the Creative Commons Attribution (CC BY) license (https:// creativecommons.org/licenses/by/ $4.0 /)$.

\begin{abstract}
The re-identification of coal workers' pneumoconiosis in Queensland in 2015 has prompted improvements in exposure monitoring and health surveillance in Australia. The potential consequences of excessive exposure to respirable dust may depend upon the size, shape and mineralogical classes of the dust. Technology has now advanced to the point that the dust characteristics can be explored in detail. This research collected respirable dust samples from four operating underground coal mines in Australia for characterization analysis using scanning electron microscopy (SEM) with energy dispersive X-ray (EDX). The research found multiple mineralogical classes present with their own particle size distributions. The variation between mines appears to have had a larger effect on particle size distribution than the differences in mining processes within individual mines. This may be due to variations in the geologic conditions, seam variation or mining conditions.
\end{abstract}

Keywords: coal mine dust lung disease; coal workers' pneumoconiosis; particle characterization

\section{Introduction}

The United States has seen a dramatic resurgence of coal workers' pneumoconiosis (CWP, also called "black lung") over the past two decades. There are notably stark regional variations in both the prevalence and severity of disease, with miners in central Appalachia being disproportionately affected [1-6]. These observations in concert with key differences in the typical mining conditions-namely the tendency to extract significant rock along with the target coal-have prompted new research to characterize dust exposures in US underground coal mines [7-9].

In Australia, CWP was re-identified in 2015, after decades with no case reports [10]. Though recent prevalence of disease in Australia is not to the extent as seen in the US, it has nonetheless had a similar effect to spur new research on dust characteristics.

Coal mine dust may contain a complex mixture of over 50 different elements and their oxides [11], and mineralogical classes of the respirable fraction may differ from the overall seam composition [12]. Beyond mass-based measures of composition, some recent research from the US has used scanning electron microscopy with energy dispersive X-ray (SEM-EDX) to characterize mineralogy and size distributions of respirable coal mine dust $[7,8,13,14]$. That work has demonstrated that dust characteristics can vary widely between and even within mines, and indicated several major sources of respirable dust.

To date, particle-level characteristics have not been determined for respirable dust in Australian underground coal mines. The purpose of the current study was to generate this data using the same SEM-EDX analysis methodology employed in the recent studies of US mines which provides for direct comparison $[7,8,13,14]$. The sampling methodologies differed slightly between the earlier US work and that reported here for Australian mines, 
as the types of cyclone elutriators used were representative of the statutory sampling devices for the respective countries. This allows for each country to correlate these results to the statutory exposure sampling data.

\section{Materials and Methods}

Samples were collected in four Australian underground coal mines. Underground coal mines in Australia are generally thick seamed and owned by large multinational corporations. This paper will discuss the samples that were analyzed from the four mines. All four were longwall mines, however the longwall at mine 3 was not operating during the sampling window and no longwall samples could be collected. Top coal caving longwalls are sometimes used in Australia to mine the thicker seams. The continuous mining machines used are miner-bolter units in longwall mines. Separate bolting units are in room and pillar (bord and pillar) mines. The sample collection methodology generally followed the procedure and protocols used in recent sampling efforts in US coal mines where the goal was to collect respirable dust for SEM-EDX analysis $[7,8,13,14]$.

In addition to sampling at the longwall face, ambient air samples were taken because other dust sources in the mine besides the cutting of the coal seam may be contributing to mine dust lung diseases (MDLDs). Sources may include stone bands within the seam, stone roof or floor, the rock dusting practices (referred to as "stone-dusting", whereby inert limestone dust is applied to mine surfaces to prevent explosion propagation), the vehicle traffic and other activities being performed outbye in the intake airway such as shoveling [7]. In some mines, diesel particulates may also be present [7]. A total of 39 samples on polycarbonate filters were collected in triplicate at 13 locations, which are listed in Table 1. Two of the longwall midface samples had all three filters analyzed for a total of 17 polycarbonate filters included in the analysis.

Table 1. Sampling set information.

\begin{tabular}{|c|c|c|c|c|c|c|}
\hline $\begin{array}{l}\text { Test } \\
\text { No. }\end{array}$ & $\begin{array}{l}\text { Mine } \\
\text { No. }\end{array}$ & $\begin{array}{l}\text { Test } \\
\text { Day }\end{array}$ & $\begin{array}{l}\text { Samples } \\
\text { Analysed }\end{array}$ & $\begin{array}{c}\text { Sample Duration } \\
\text { (min) }\end{array}$ & Location Code & Location \\
\hline 1 & 1 & 1 & 1 & 169 & MG & Longwall Maingate hung from Shield 3 \\
\hline 2 & 1 & 1 & 3 & 109 & MF & Longwall Midface shield 76 on pan line \\
\hline 3 & 1 & 2 & 1 & 297 & $\mathrm{CM}$ & Continuous Miner Development Heading \\
\hline 4 & 1 & 2 & 1 & 314 & RW & Development Roadway $60 \mathrm{~m}$ back from auxiliary fan \\
\hline 5 & 2 & 3 & 1 & 231 & RW & Development Roadway belt road $15 \mathrm{~m}$ from auxiliary fan \\
\hline 6 & 2 & 3 & 1 & 243 & $\mathrm{CM}$ & Continuous Miner in Development Heading \\
\hline 7 & 2 & 4 & 3 & 251 & MF & Longwall Midface Shield 76 \\
\hline 8 & 2 & 4 & 1 & 270 & MG & Longwall Maingate Shield 10 \\
\hline 9 & 3 & 5 & 1 & 310 & RW & Mains Development Conveyor Roadway \\
\hline 10 & 3 & 5 & 1 & 242 & $\mathrm{CM}$ & Continuous Miner in Mains Development \\
\hline 11 & 4 & 6 & 1 & * & $\mathrm{CM}$ & Continuous Miner \\
\hline 12 & 4 & 7 & 1 & * & MG & Longwall Maingate \\
\hline 13 & 4 & 7 & 1 & $*$ & MF & Longwall Midface \\
\hline
\end{tabular}

Characterization samples were collected from the mines and each filter was given a unique number. There were 1400 particles analyzed for the mineralogical class on each filter. The sample code is made up of the mine number (1-4), the two letters for the location code and the last two digits of the filter ID. The location coding includes longwall maingate $(\mathrm{MG})$, longwall mid-face (MF), continuous miner (CM) and roadway (RW) samples as shown in Table 1. For example, the code for the first sample is 1CM_01, which is from mine 1 , located at the continuous miner (CM) and is filter number 1001. 
Samples were collected with SKC plastic respirable cyclone elutriators (model 225-6937) on Zefon $37 \mathrm{~mm}$ polycarbonate filters with 0.4-micron pore size, both ordered through AirMet Scientific (Newstead, QLD, Australia). Cassettes and cyclones were packed in the laboratory at the Sustainable Minerals Institute (The University of Queensland) and flown to the mine site for sampling in checked baggage. After collection, filters were removed from the SKC cassettes and placed in $37 \mathrm{~mm}$ polystyrene cassettes. The filters remained in the polystyrene cassettes for transport in carry-on luggage for the return journey and to be mailed to Virginia Tech for analysis.

SKC AirChek 300 pumps were used in the Queensland mines and Casella Apex 2 pumps in the New South Wales Mines. Pumps were field calibrated with an SKC Field rotameter (within calibration). Metal frames were set up to hold four cyclones in position for simultaneous sampling (Figure 1a). The SKC cyclones were operated at $2.2 \mathrm{~L} / \mathrm{min}$ (Notably, shortly after the dust sampling for this study, a revised flow rate sample collection was published for the SKC cyclones due to an oversampling issue of up to $30 \%$ (i.e., at $2.2 \mathrm{~L} / \mathrm{min}$, the cyclones were found to have a larger cutpoint than desired for respirable dust sampling [15].). At the revised flow rate of $3.0 \mathrm{~L} / \mathrm{min}$ the measured $\mathrm{D}_{50}$ was $5 \%$ higher than the target $\mathrm{D}_{50}$ of 4.00 microns.

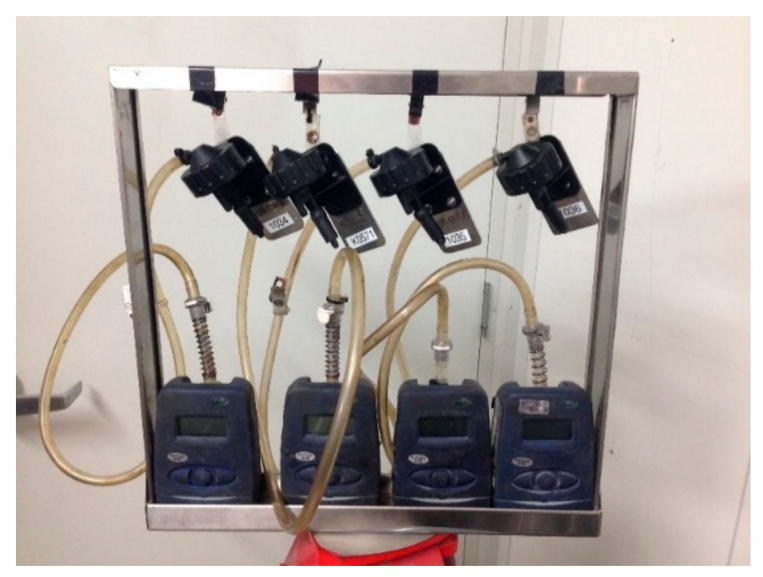

(a)

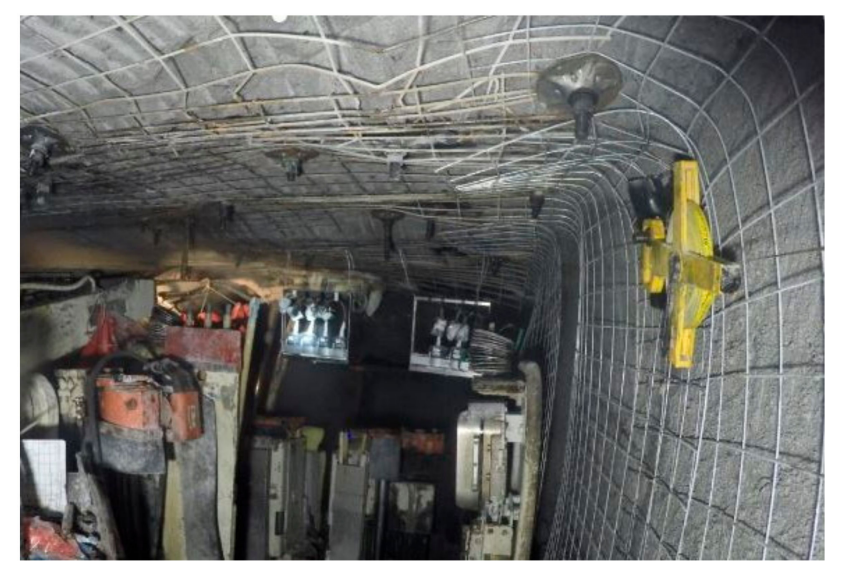

(b)

Figure 1. (a) Photo of sampling trains set up inside the frame. (b) Photo of sampling frames installed on continuous miner during sampling.

The sampling frame sat on a tripod at approximately $1.8 \mathrm{~m}$ or breathing height for roadway samples or was mounted as close as practicable to breathing height for production samples. On continuous miner bolter machines, the frame was mounted on equipment close to where the workers who were installing roof-bolts were positioned (Figure 1b). 
For the longwall samples the frame was mounted just inby the maingate corner or to the panline for midface samples.

The filters were shipped to Virginia Tech (Blacksburg, VA, USA) for SEM-EDX analysis and one random filter sample from each location was analyzed, with the exception of locations No. 2 and 7 from which all three filters were analyzed. Preparation and analysis followed the procedures outlined in Sarver et al. (2019) and are briefly summarized here: A single 9-mm subsection was cut from each filter and sputter coated with $\mathrm{Au} / \mathrm{Pd}$. Then it was analyzed using an FEI Quanta 600 FEG environmental scanning electron microscope (ESEM) (Hillsboro, OR, USA) equipped with a backscatter electron detector (BSD) and a Bruker Quantax 400 EDX spectroscope (Ewing, NJ, USA); the SEM-EDX was operated at $1000 \times$ magnification, $12.5 \mathrm{~mm}$ working distance, $15 \mathrm{kV}$ accelerating voltage and $5.5 \mu \mathrm{m}$ spot size. Particle sizing (in range of 1-20 microns) and mineralogy classification was done by a computer-controlled routine using Bruker Esprit software (Version 1.9.4); classification criteria are shown in Table 2.

Table 2. SEM-EDX classification criteria for 1-10-micron particles (modified from [7]).

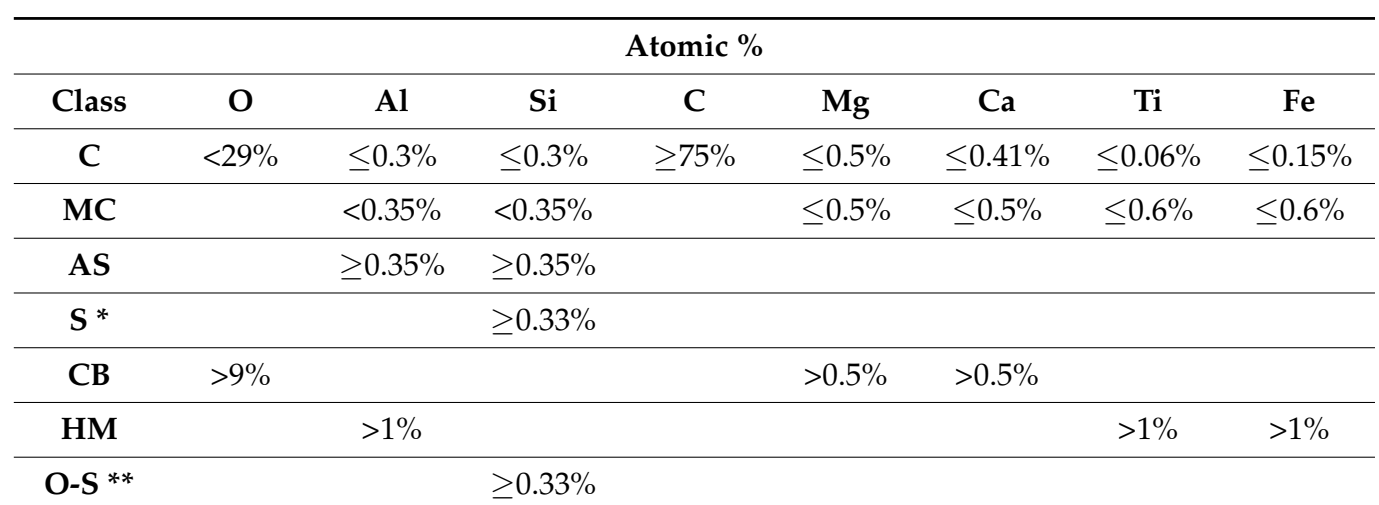

* Additional limits for $\mathrm{S}: \mathrm{Al} / \mathrm{Si}<1 / 3$ and $\mathrm{Si} /(\mathrm{Al}+\mathrm{Si}+\mathrm{Mg}+\mathrm{Ca}+\mathrm{Ti}+\mathrm{Fe}) \geq 0.5$. ${ }^{* *}$ Additional limits for $\mathrm{OS}$ : $\mathrm{Si} /(\mathrm{Al}+\mathrm{Si}+\mathrm{Mg}+\mathrm{Ca}+\mathrm{Ti}+\mathrm{Fe})<0.5$.

A total of 1400 particles per sample were classified. It should be noted that while the C class (carbonaceous) is generally expected to include mostly coal dust in the supra-micron range, diesel particulates may also influence this class, where present. Although only 1400 particles per sample were classified by mineralogy, many more particles were also sized by the computer-controlled SEM-EDX routine (i.e., between 7805 and 29,993 per sample). This paper reports on the particle size distribution (PSD) for the particles that were classified by mineralogy.

The abbreviations of the mineralogical classes used throughout this paper are aluminosilicates (AS), carbonaceous (C), carbonates (CB), heavy metals (HM), mixed carbonaceous $(\mathrm{MC})$, other $(\mathrm{O})$, other silicates (O-S) and silica $(\mathrm{S})$.

\section{Results}

Mineralogy was found to differ between mines and locations within mines. Figure 2 shows the mineralogy classes for the samples analyzed in this study. The roadway dust in mines 1 and 2 show a significant percentage of carbonates, while the roadway dust found in mine 3 is predominantly aluminosilicates with some silica. Mines 1 and 2 showed a large percentage of coal on the continuous miner and longwall. 


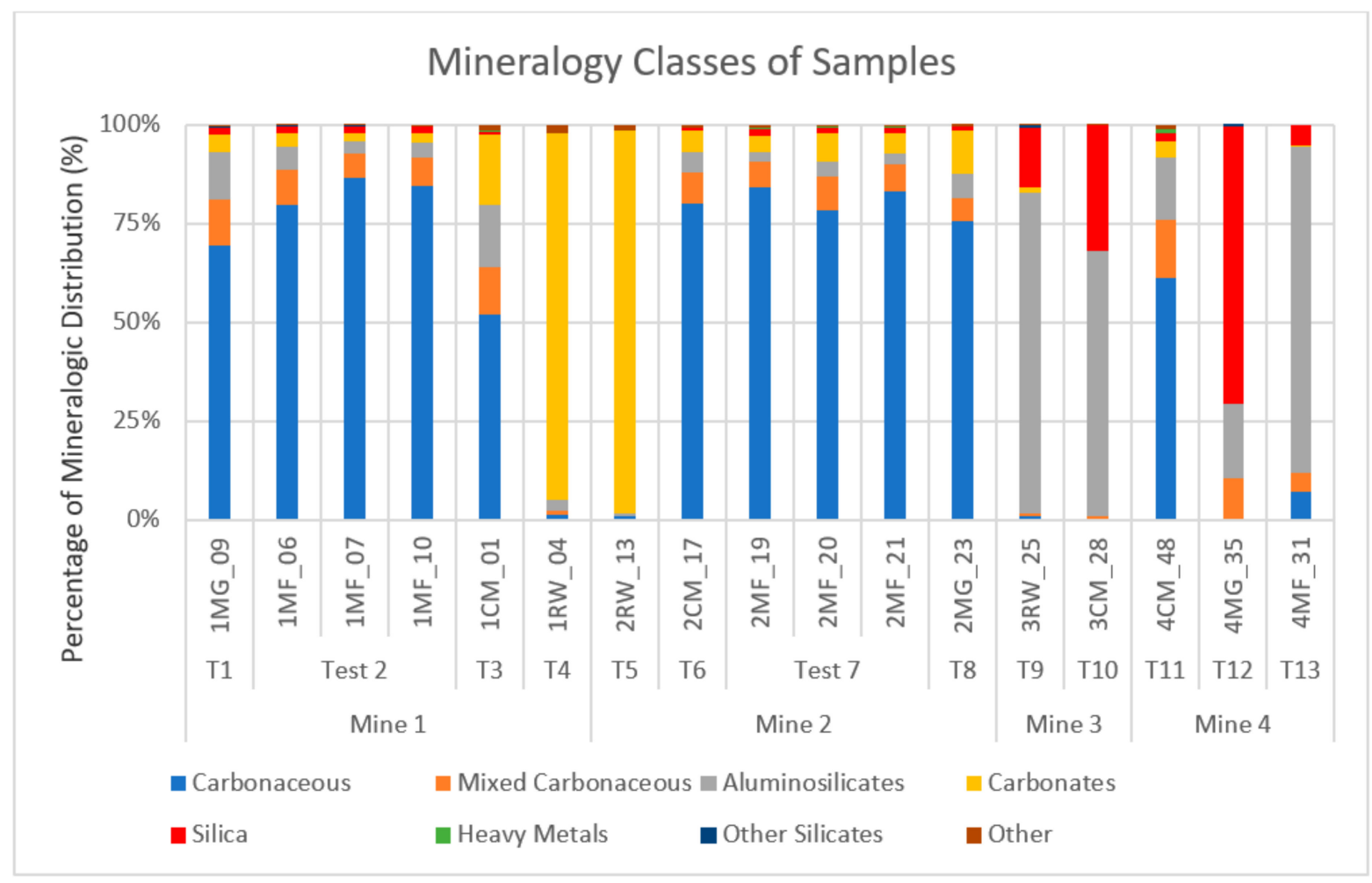

Figure 2. Mineralogy classes of samples for tests 1-13 in mines 1-4.

The cumulative particle size for the samples in mines 1 and 2 are shown in (a) and (b) of Figure 3, respectively. The x-axis shows the particle sizes from 1 to 7 microns, while the $y$-axis displays the cumulative percentage of particles. Lines closer to the top left indicate a finer PSD while those closer to the bottom right indicate a coarser PSD. The continuous miner sample is represented by the dashed line. The longwall maingate samples are represented by the lighter shaded lines with the square markers. The darkest shade denotes the longwall midface samples which were taken in triplicate. The narrow deviation between midface sample lines indicates good agreement between cyclones.

The grey lines represent the samples taken in the mine roadways which contain a significant number of carbonates. The carbonates are most probably introduced into the mine through stone dusting practices. The data obtained from mines 1-3 show that the percentage of finer particles measured by the cyclone elutriator is greater in roadways than at working faces (continuous miner or longwall). No roadway sample was taken from mine 4 for comparison. The three mines showed similar particle size distributions for roadway dust, which is better illustrated in Figure 4.

The continuous miner samples represented by the dashed lines generally have the coarsest particle size distribution of the samples taken in mines 1, 3 and 4 . For mine 2 the PSD of the continuous miner sample crosses over the longwall maingate sample line.

When samples are compared by the types of cutting equipment, namely, longwall or continuous miner, the mine from which the samples were taken appears to have a stronger effect on the PSD than the equipment type used to cut it as evidenced by the spread of PSDs. There may be several reasons for this including differences in geology between the seams, changes in rock strength, mining conditions, cutting speed, wear level of cutter picks and dust suppression systems used. The mineralogy distributions of these samples vary significantly as seen in Figure 2. 


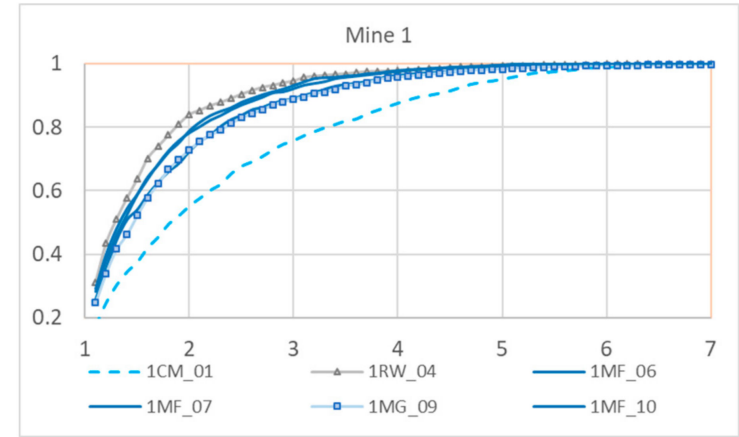

(a)

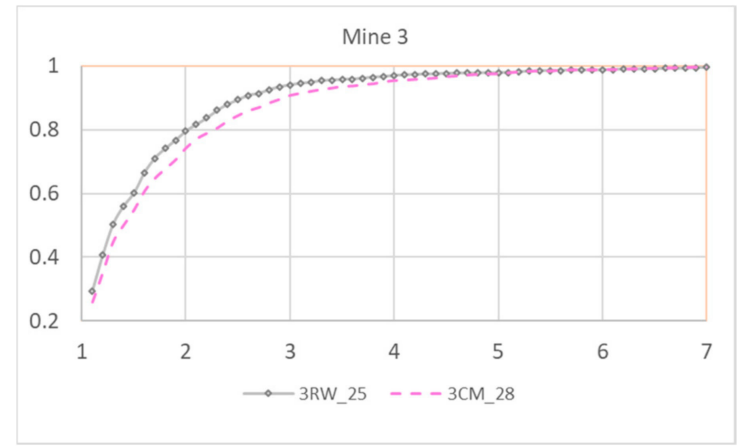

(c)

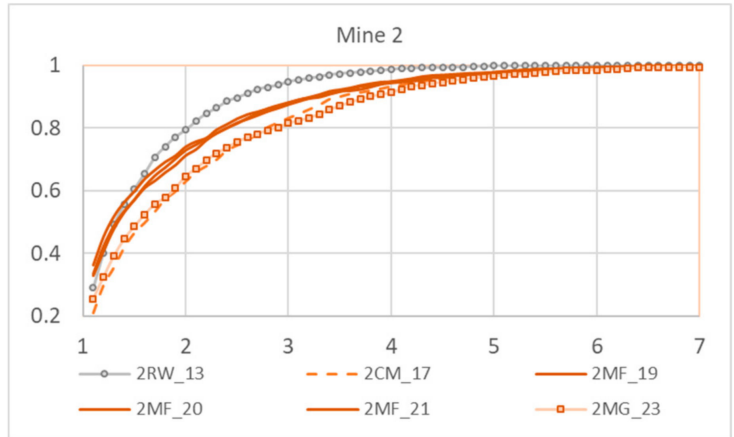

(b)

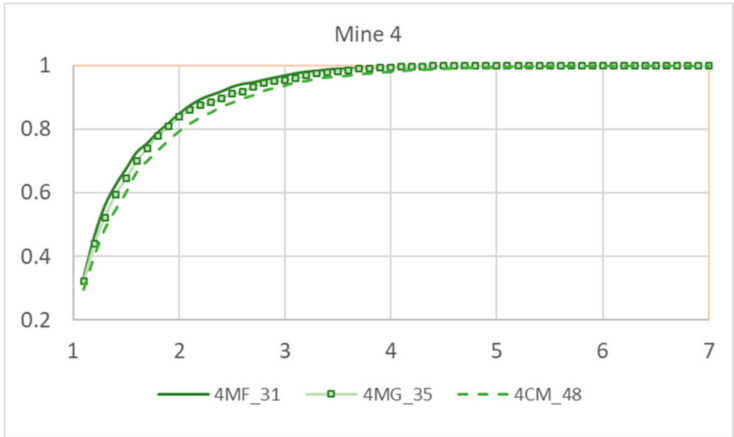

(d)

Figure 3. Cumulative particle size by sample. (a) Mine 1 samples, (b) Mine 2 samples, (c) Mine 3 samples and (d) Mine 4 Sammples. $\mathrm{X}$-axis $=$ particle size (microns) and $\mathrm{y}$-axis = cumulative percentage.

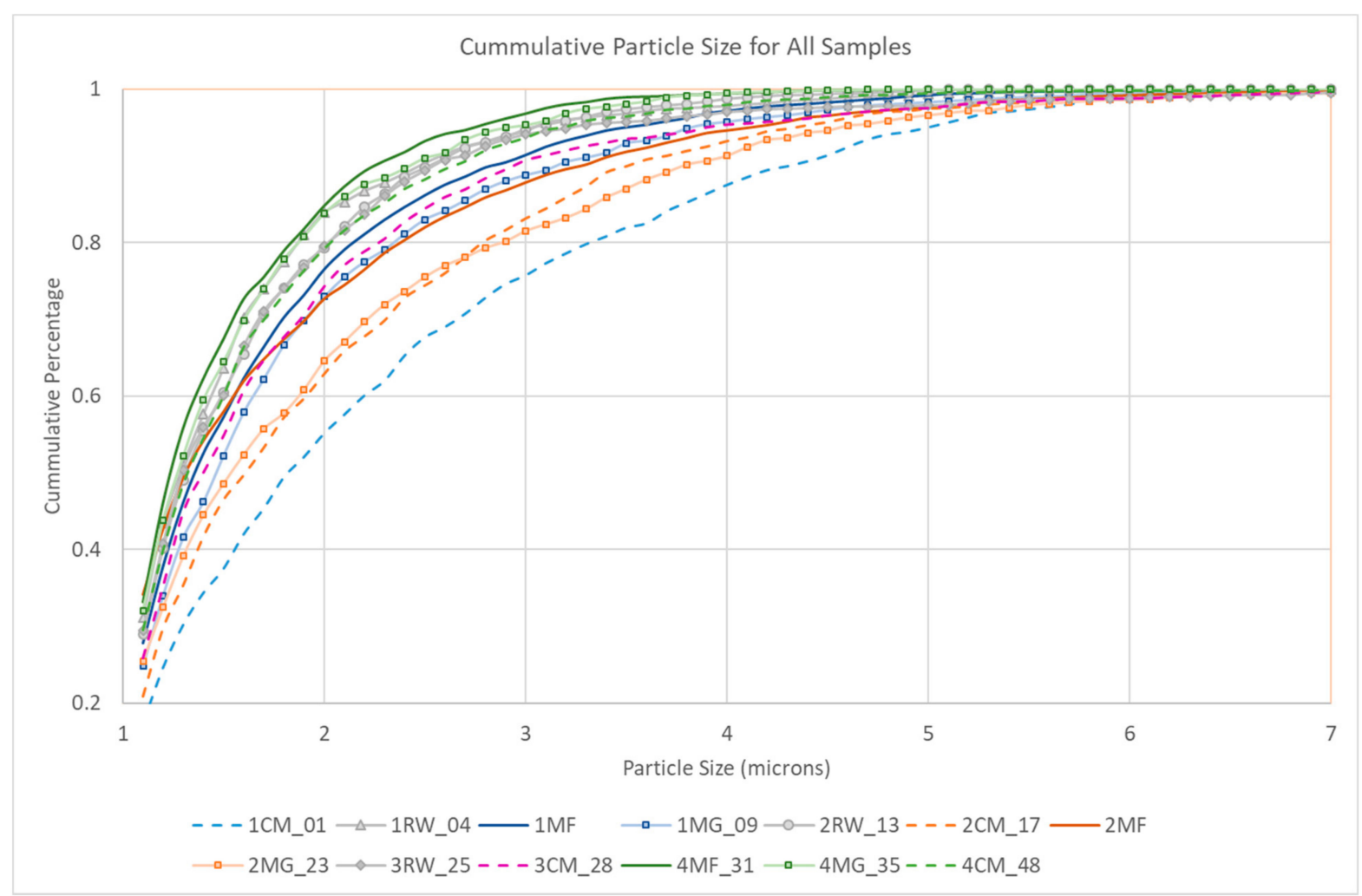

Figure 4. Cumulative particle size for all samples. $\mathrm{X}$-axis $=$ particle size (microns) and $\mathrm{y}$-axis $=$ cumulative percentage $(\%)$. 
The overall PSDs at the maingate are slightly finer than the PSD at longwall midface as shown in Figure 3. In mine 1, the maingate sample slightly crosses one of the midface samples. For instance, while 55\% of the particles in the CM section of mine 1 are less than 2 microns, $85 \%$ of the particles on the LW midface are less than 2 microns. The exposures and health hazards will change from mine to mine based on the changes in PSD and mineralogical classes.

Figure 4 shows the cumulative particle size distribution of all samples. The triplicate longwall midface samples have been averaged to simplify the chart. Mine 4 has the finest PSDs of the mines, followed by mine 3 and then mine 2. Mine 1 had the largest range in PSDs producing the coarsest sample as well as finer samples closer to the PSDs of mine 3.

This technique is able to determine the particle size distribution for the various mineralogical classes within samples from the data on the individual particles. Each mineralogical class has its own PSD. The PSD of a mineralogical class may also vary by location within the mine. All of the carbonaceous particles from the three roadway samples are less than two microns in size as well as the mine 2 longwall maingate sample.

Notably, the SEM data (using all of the particles that were sized) indicated that there were indeed non-trivial numbers of oversized particles in some samples. For example, 146 of 26,381 particles sized in the continuous miner sample from mine 3 were $>10$ microns. While this accounts for only $0.6 \%$ by particle count, it could account for some $18 \%$ of particle volume (based on the measured PSD and assuming spherical particles). The return sample from mine 3 also showed relatively many oversized particles (i.e., 51 of 20,255, which represents $0.3 \%$ by particle number but perhaps $16 \%$ by particle volume).

The automated routine could not distinguish coal from diesel particulates as they are both carbon-based particles. Photographic images of the filters reveal a large quantity of diesel particulate present in the samples as shown in Figure 5b. The diesel is the clusters or chains of small spherules on the filter. The black dots are 0.4-micron holes in the filter.

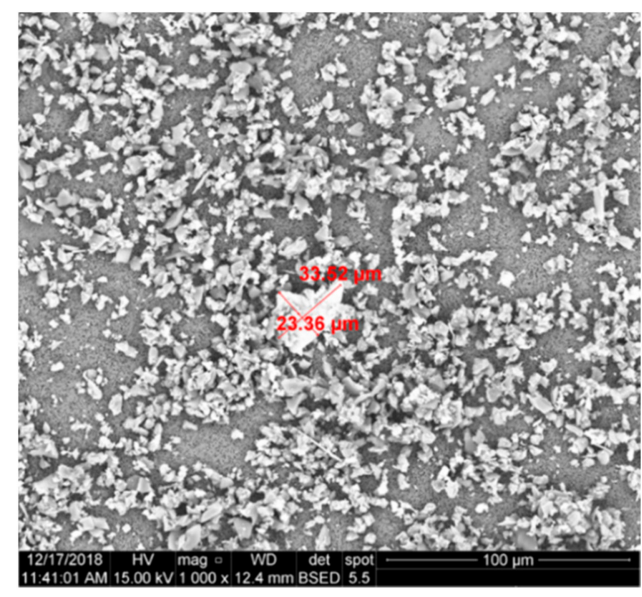

(a)

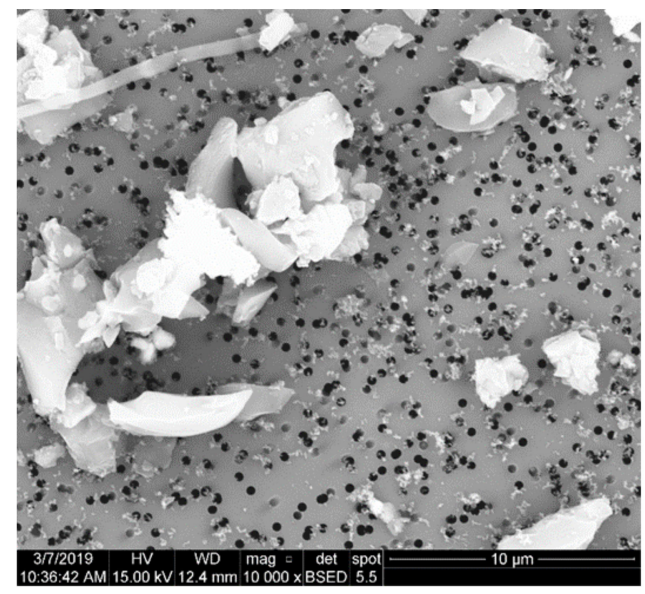

(b)

Figure 5. Photographs of dust particles collected showing (a) an oversized ( $>10$ micron) particle and (b) clear presence of very fine diesel particulates.

The PSDs for silica for each sample is shown in Figure 6 based on 0.1-micron size bins. While the overall PSD of the maingate and midface samples for mine 1 were very similar, there is a much wider spread in the silica distribution. The silica in the maingate of mine 4 has a finer PSD than the midface sample. No silica was found in the roadway samples of mines 1 and 2 .

The PSDs for the mineralogical components of various samples are shown in Figure 7. The different mineralogical components may vary quite significantly in PSD. The PSD of the carbonaceous fractions varies significantly in these samples. In (a) 2 microns accounts 
for $59 \%$ of carbon particles while in (c) and (d) $69 \%$ and $87 \%$ of particles are less than 2 microns, respectively. In (b) the top size of carbonaceous particles is 1.6 microns.

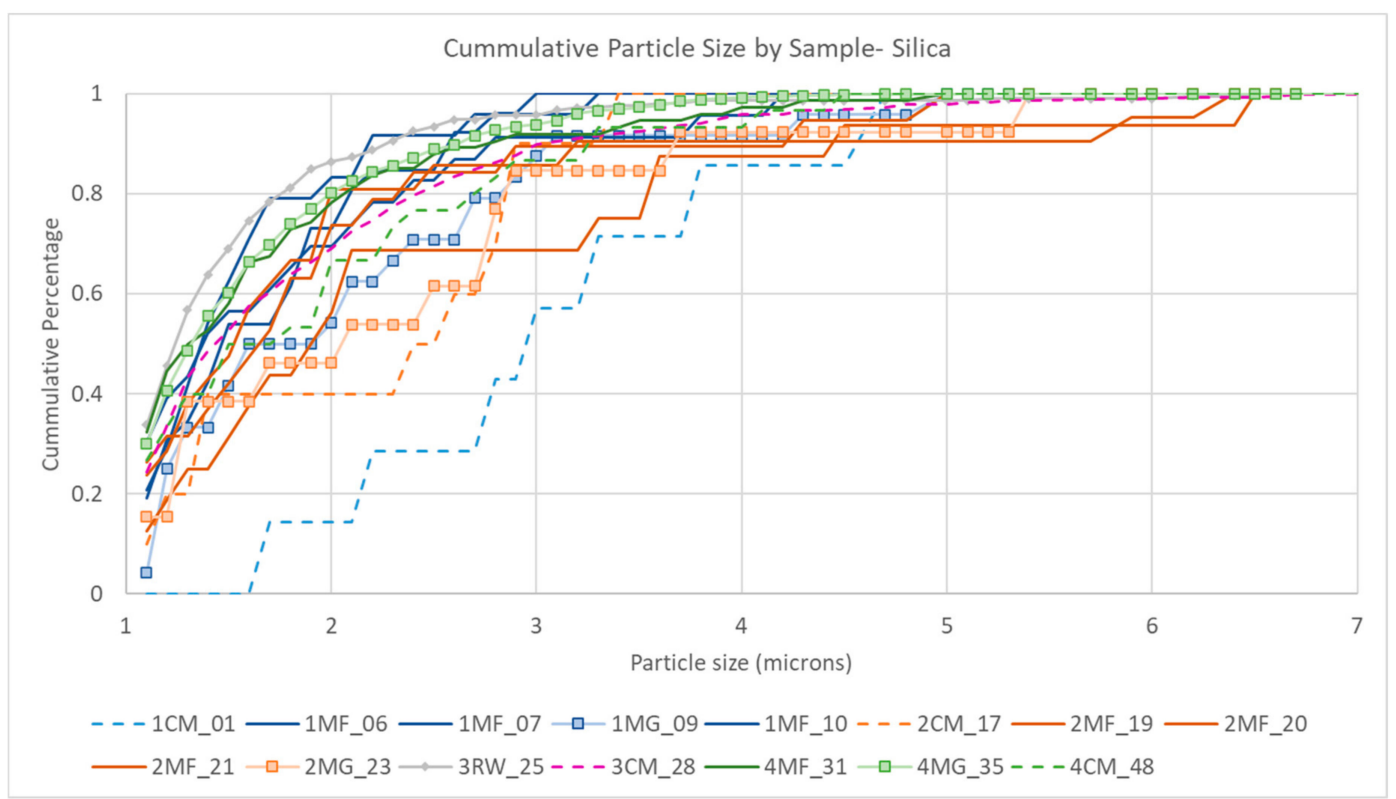

Figure 6. Cumulative particle size for silica particles. $X$-axis $=$ particle size (microns) and $y$-axis $=$ cumulative percentage $(\%)$.

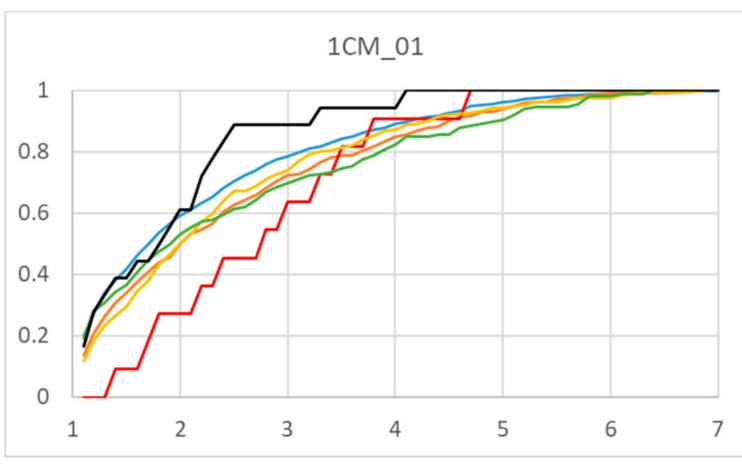

(a)

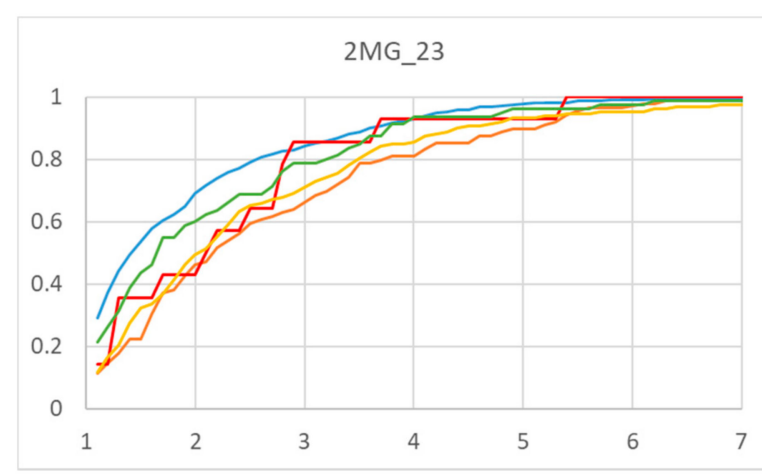

(c)

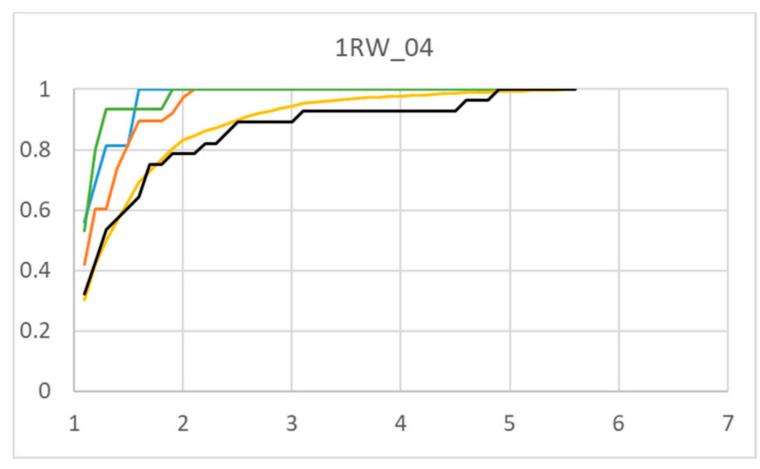

(b)

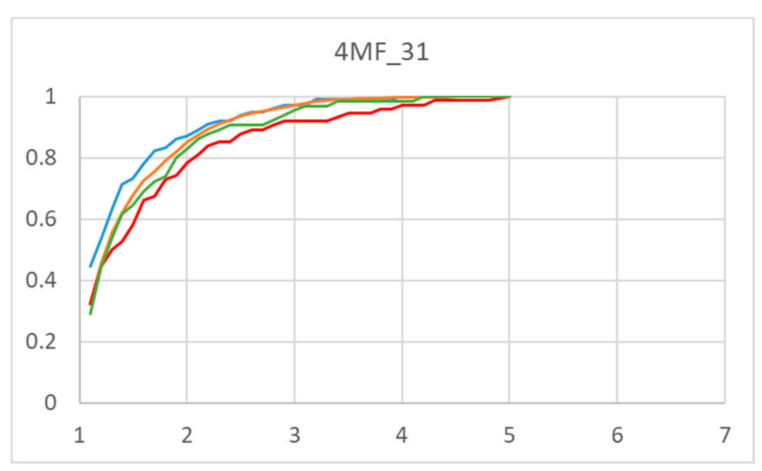

(d)

Figure 7. Particle size distributions of various mineralogical classes in samples. (a) Mine 1 continuous miner, (b) Mine 1 roadway, (c) Mine 2 longwall maingate, (d) Mine 4 longwall midface. X-axis = particle size (microns) and $y$-axis = cumulative percentage. 
The width of the distributions can also be noted from this figure. Some samples may have a wider distribution like (c) or a narrower distribution such as (d). In part (a) the silica and other PSD is significantly different than the distributions of the other four components which more closely track each other. Mineralogical classes with less than 5 particles are not shown. Not all mineralogical classes are found in every sample.

\section{Discussion}

This is the first time this type of testing has been conducted on ambient air samples from Australian underground coal mines. It allows for identification of the size and mineralogical class of individual particles. Historically, particle size distributions have been calculated for total dust content and did not differentiate by mineralogical class.

The mineralogical class was found to vary by mine and to a lesser extent by location within individual mines. On average, there was a greater coal content in the Australian samples than many of the US samples [13]. A number of aluminosilicate particles were identified in some samples; for both countries there is currently no exposure standard for this class of particulates. A significant quantity of aluminosilicates have been found during analysis of lung particle burden [16].

One limitation of this methodology is the inability to differentiate the carbonaceous fraction between coal and diesel particulates. Diesel particulate matter was visible on SEM photos of the filters. While generally much finer than the dust particles, some aggregates and chains can certainly exceed the 1-micron threshold used for the bottom size on the SEMEDX analysis. The overall effects of diesel particulates in the mine samples analyzed here are likely to cause an increase in the carbonaceous percentage and to skew the carbonaceous size distribution finer.

Variations in PSD and mineralogical class within the ambient air of the mine may correlate to different levels of health hazards. Additional research is needed to determine the extent of the variation in toxicity. One of the issues with relying on dust mass for the exposure standard is the variation in the PSD within that dust that may be present. A greater number of small particles can be more hazardous, as evidenced by Mischler et al. [17].

Despite the greatest differences in PSD being between mines, the PSD variance within individual mines should not be ignored and has potential health implications. Some tasks may expose workers to a greater number of smaller particles which penetrate deeper into the lungs while other workers may be exposed to a smaller number of large particles despite them having similar respirable dust exposure masses. Traditional analysis would have concluded their risk as the same but workers exposed to large quantities of small particles may be at higher risk of developing mine dust lung diseases [17]. Roadway samples were found to generally contain finer dusts than other locations within the mine. While the quantity of dust present in roadways may be lower than the working faces, this finer PSD may indicate that more of these particles may penetrate into the alveolar region of the lungs. Understanding variation in particle burden may improve exposure monitoring and control to reduce this risk.

\section{Conclusions}

Various mineralogical classes contained within the dust may pose more of a health hazard than others. Different sources of dust within the mine will have different mineralogical distributions and different particle size distributions. Understanding the true exposures of workers though characterization studies will be beneficial for further research into understanding the health implications. Characterization data should be used as input to future lung deposition and toxicity studies that reflect the variations in dust sources, PSDs and mineralogical classes to which workers are exposed and their cumulative effects. These in turn could feed into molecular epidemiological studies to further our understanding in the field. 
Understanding the mineralogical classes and PSD may also be helpful in implementing controls. This study only looked at the mines under normal operating conditions. Coal cutting parameters such as speed, depth or bit type could also be examined in future studies to see how these parameter changes effect respirable dust.

Author Contributions: Conceptualization, N.L. and E.S.; methodology, C.K., E.S.; software, C.K. and E.S.; validation, C.K., E.S. and N.L.; formal analysis, N.L.; investigation, N.L.; resources, N.L. and E.S.; data curation, C.K., E.S. and N.L.; writing—original draft preparation, N.L.; writing—review and editing, E.S., C.K., K.J. and D.C.; visualization, N.L.; supervision, D.C. and K.J.; project administration, D.C.; funding acquisition, D.C. All authors have read and agreed to the published version of the manuscript.

Funding: This research was funded by The University of Queensland and Resources Safety and Health Queensland.

Acknowledgments: The authors would like to thank the mines for their facilitation of the sample collection visits.

Conflicts of Interest: The authors declare no conflict of interest.

\section{References}

1. Almberg, K.S.; Halldin, C.N.; Blackley, D.J.; Laney, A.S.; Storey, E.; Rose, C.S.; Go, L.H.T.; Cohen, R.A. Progressive Massive Fibrosis Resurgence Identified in U.S. Coal Miners Filing for Black Lung Benefits, 1970-2016. Ann. Am. Thorac. Soc. 2018, 15, 1420-1426. [CrossRef] [PubMed]

2. Blackley, D.J.; Halldin, C.N.; Laney, A.S. Continued Increase in Prevalence of Coal Workers' Pneumoconiosis in the United States, 1970-2017. Am. J. Public Heal. 2018, 108, 1220-1222. [CrossRef] [PubMed]

3. Blackley, D.J.; Crum, J.B.; Halldin, C.N.; Storey, E.; Laney, A.S. Resurgence of Progressive Massive Fibrosis in Coal Miners-Eastern Kentucky, 2016. MMWR. Morb. Mortal. Wkly. Rep. 2016, 65, 1385-1389. [CrossRef] [PubMed]

4. Hall, N.B.; Blackley, D.J.; Halldin, C.N.; Laney, A.S. Current Review of Pneumoconiosis Among US Coal Miners. Curr. Environ. Heal. Rep. 2019, 6, 137-147. [CrossRef] [PubMed]

5. Doney, B.C.; Blackley, D.; Hale, J.M.; Halldin, C.; Kurth, L.; Syamlal, G.; Laney, A.S. Respirable coal mine dust in underground mines, United States, 1982-2017. Am. J. Ind. Med. 2019, 62, 478-485. [CrossRef] [PubMed]

6. Antao, V.C.D.S.; Petsonk, E.L.; Sokolow, L.Z.; Wolfe, A.L.; A Pinheiro, G.; Hale, J.M.; Attfield, M.D. Rapidly progressive coal workers' pneumoconiosis in the United States: Geographic clustering and other factors. Occup. Environ. Med. 2005, 62, 670-674. [CrossRef] [PubMed]

7. Sarver, E.; Keles, C.; Rezaee, M. Characteristics of respirable dust in eight appalachian coal mines: A dataset including particle size and mineralogy distributions, and metal and trace element mass concentrations. Data Brief 2019, 25, 104032. [CrossRef] [PubMed]

8. Sarver, E.; Keles, C.; Rezaee, M. Beyond conventional metrics: Comprehensive characterization of respirable coal mine dust. Int. J. Coal Geol. 2019, 207, 84-95. [CrossRef]

9. National Academies of Sciences, Engineering and Medicine. Monitoring and Sampling Approaches to Assess. Underground Coal Mine Dust Exposures; National Academies of Sciences, Engineering and Medicine: Washington, DC, USA, 2018.

10. Coal Workers Pneumoconiosis Select Committee. Black Lung White Lies: Inquiry into the re-identification of Coal Workers' Pneumoconiosis in Queensland; Report No.2; Queensland Governement: Brisbane, Australia, 2017.

11. IARC Working Group on the Evaluation of Carcinogenic Risk to Humans. Silica, some silicates, coal dust and para-aramid fibils. In IARC Monographs on the Evaluation of Carcinogenic Risks to Humans; International Agency for Research on Cancer: Lyon, France, 1997; Volume 68.

12. Schatzel, S.J. Identifying sources of respirable quartz and silica dust in underground coal mines in southern West Virginia, western Virginia, and eastern Kentucky. Int. J. Coal Geol. 2009, 78, 110-118. [CrossRef]

13. Johann-Essex, V.; Keles, C.; Rezaee, M.; Scaggs-Witte, M.; Sarver, E. Respirable coal mine dust characteristics in samples collected in central and northern Appalachia. Int. J. Coal Geol. 2017, 182, 85-93. [CrossRef]

14. Johann-Essex, V.; Keles, C.; Sarver, E. A Computer-Controlled SEM-EDX Routine for Characterizing Respirable Coal Mine Dust. Minerals 2017, 7, 15. [CrossRef]

15. SKC. SKC Plastic Cyclone Notice; Specialists in Air Sampling Technologies: Dorset, UK, 2018.

16. Abraham, J.L.; Crawford, J.A.; Scalzetti, E.; Kramer, L.G. Analysis of lung particle burden in a 28 year old man with rapidly progressive coal worker's pneumoconiosis (Accelerated silicosis). Am. J. Respir. Crit. Care Med. 2020, 307, A7074.

17. Mischler, S.E.; Cauda, E.G.; Di Giuseppe, M.; McWilliams, L.J.; Croix, C.S.; Sun, M.; Franks, J.; Ortiz, L.A. Differential activation of RAW 264.7 macrophages by size-segregated crystalline silica. J. Occup. Med. Toxicol. 2016, 11, 57. [CrossRef] [PubMed] 